\title{
J. N. Rosen: un pionero controvertido en el abordaje psicoanalítico de la psicosis.
}

\author{
J. N. Rosen: a controversial pioneer in the \\ psychoanalytic approach into psychosis.
}

RESUMEN: En este trabajo se analiza la trayectoria vital y profesional de J. N. Rosen, un pionero controvertido en el abordaje de la psicosis desde la óptica psicoanalítica.

PALABRAS CLAVES: psicosis, análisis directo, psiquiatría psicoanalítica directa.
ABSTRACT: This paper analyses the life and the work of J. N. Rosen, a controversial pioneer in the approach of psychosis from a psychoanalytic perspective.

KEY WORDS: psychosis, direct analysis, direct psychoanalytic psychiatry.

Acontecimientos vitales y profesionales más señeros de su semblanza.

John Nathaniel Rosen (1902-1983) nació en Brooklyn (Nueva York, EE UU) (1), ignorándose el ambiente socio-educativo y familiar en que se desarrollaron sus primeros años de infancia y juventud. No obstante, tal laguna biográfica pudiera ser cubierta por M. Brand (1906-1980), escritor y poeta estadounidense, que en su libro Sueño salvaje (1968) juzgamos recrea noveladamente la vida de Rosen, encarnada ésta en la del Dr. John N. Marks, que, como aquél, tiene tres hijos (John, Robert y Nancy), dos de cuyos nombres coinciden con los de los vástagos reales de Rosen. Brand, cuya novela se sitúa entre 1943 y 1946, se entrevistó con Rosen y conoció de primera mano su trabajo con psicóticos 20 años antes de que tal novela fuera publicada (2). Siguiendo esto, la familia raíz de Rosen, de etnia judía y origen ruso, habría emigrado a Estados Unidos, estando compuesta por cuatro hermanos, que como John habrían sido educados en una atmósfera familiar caracterizada por un padre agresivo, que les inflingía duros castigos físicos para que acataran normas y preceptos judíos, sin ofrecer a cambio explicación alguna, lo que John vivenciaba retrospectivamente como muy doloroso. En tal ambiente, destaca también la figura valedera de gran respeto de la abuela paterna, mujer muy religiosa, limitándose el papel de la madre al de esposa sumisa y responsable de las tareas domésticas (3). Dejando a un lado tales conjeturas, es conocido que en 1928 comienza sus estudios de medicina, de la que inicialmente le atraen la patología y la medicina interna, para unos años después la psicoso- 
ORIGINALES Y REVISIONES

mática (de la que varias décadas más tarde reconocerá lo útil de estar instruido en ella para trabajar con psicóticos) y el saber psicoanalítico, viraje intelectual que justifica al evidenciar cómo sujetos que eran tratados de dolencias aparentemente de origen orgánico, una vez realizadas las pertinentes pruebas físicas, no se les detectaban anomalías biológicas a partir de las cuales explicar sus síntomas (4). Así, en busca de respuestas, y respetando las exigencias del psicoanálisis, inicia su propio análisis personal, cuyo analista se desconoce, aunque de admitir lo recreado por Brand (3), especulando nuevamente, corroboramos la gran similitud que existe entre la trayectoria vital-profesional de H. Nunberg (1883-1970) y la del analista de Rosen corporeizado en tal relato, quien, como aquél, se había formado en psiquiatría bajo la guía de E. Bleuler (1857-1939) y C. G. Jung (18751961) en el prestigioso Hospital Mental de Burghölzli (o Clínica Psiquiátrica de la Universidad de Zúrich); era asimismo amigo íntimo de P. Federn (1871-1950), a quien Rosen llegó a conocer personalmente en la década de los 40 del siglo $\mathrm{XX}$, y quien como su analista se había exiliado a Estados Unidos huyendo del nazismo, estableciéndose finalmente en Nueva York (5). Independientemente de la identidad de tal analista, acerca del curso de su análisis, cuya duración fue de 11 años, según el propio Rosen confiesa (6), manifiesta que aprendió que hay una mente inconsciente, capaz de crear fantasías que poseen la fuerza de la realidad, percibiendo que los principios de funcionamiento psíquico son similares para todos los sujetos (4). De igual forma su analista y él se percataron de la especial destreza que poseía para aprehender el contenido psicológico manifiesto y el material onírico (6); señala también cómo los hallazgos freudianos le condujeron a su orientación en psiquiatría, juzgando a éstos las bases teóricas en donde se apoya su psicoanálisis directo (4). Paralelamente, recibe cursos y seminarios en el Instituto Psicoanalítico de Nueva York, a la vez que trabaja como psiquiatra, aunque con una perspectiva farmacológica, en la Clínica Neuropsiquiátrica del hospital Monte Sinai (1).

De su formación y trayectoria profesional se sabe también que, en octubre de 1943, fue residente en psiquiatría en el hospital estatal de Brooklyn, completando su período formativo y experiencial hasta septiembre de 1945 en el Instituto y hospital psiquiátrico estatal de Nueva York. Ejerce también como psiquiatra un tiempo en el hospital estatal de Boston, al que en 1947 invitó a P. Federn para que les impartiera una conferencia, quedando entonces impresionado por éste hasta llegar a modificar su perspectiva teórico-técnica acerca de la psiquiatría (7). Allí, junto a Rosen, como enfermera psiquiátrica, trabajaba Ms. Wolf, quien le siguió al trasladarse al hospital estatal de Filadelfia, y quien, en su Suiza natal, se había formado bajo el magisterio de M.-A. Séchehaye (1887-1964), siendo después presentada a P. Federn en los años 40 por el Dr. H. Meng (1887-1975), analizado suyo y luego también analista. 
ORIGINALES Y REVISIONES

Después del citado recorrido curricular-profesional en instituciones públicas, Rosen iniciará su práctica privada en la ciudad de Nueva York y en el condado de Bucks, en Pensilvania (8), ejerciendo también en Boca Raton (Florida) más de 30 años, donde adquirió una propiedad y pasaba la época invernal (de noviembre a mayo) (9), regresando después periódicamente a su actividad en Pensilvania. En 1946 ve la luz su trabajo Método para resolver la excitación catatónica aguda, y en 1947 firmado también por él Tratamiento de la psicosis esquizofrénica con terapia analítica directa. En éste, junto al prefacio de los editores y las serias reflexiones de seis psiquiatras (J. Einsenbud, P. Federn, P. Hoch, J. Meiers, M. Schmideberg y H. Spotnitz), cinco de ellos analistas, Rosen ofertaba un novedoso tratamiento para la esquizofrenia, al que llamó análisis directo, técnica psicoterapéutica activa con la pretendía acceder al sistema delusivo de sus pacientes, quienes debían encarar y contrastar la realidad (10). Paralelamente realiza disertaciones y demostraciones públicas del análisis directo, como la que en 1948 lleva a cabo en Londres durante una visita (11), técnica a la que en 1962 otra vez llamará psicoanálisis directo, tal como ya le sugirió P. Federn en 1947, enfatizando así la orientación esencialmente freudiana de su trabajo teórico-clínico, como él mismo manifiesta en el prefacio a su Psiquiatría psicoanalítica directa (4). Como colectivos entre los que realiza tal labor difusora están organizaciones y grupos profesionales como la Psychiatric Society of Massachussets, la Psychoanalytic Society of Nueva York, el grupo psicoanalítico de Washington o el personal cualificado de la clínica Menninger (1), en cuya revista en 1950 aparecerá el artículo La función de supervivencia de la esquizofrenia, que, al igual que otros ya referidos de Rosen, será luego incluido en el libro Análisis directo: artículos escogidos (1953), que dedica a su esposa (8) y del que 15 años después será una continuación Artículos seleccionados acerca del psicoanálisis directo. Vol. 2 (1968), que vuelve a dedicar a su mujer; ambos títulos, traducciones nuestras del inglés, varían de las realizadas en nuestra lengua; versión ésta que, como la original norteamericana, se editó en 2 tomos, el primero de los cuales titulado Psicoanálisis directo. Tratamiento de las psicosis sin medicamentos, apareció en 1975; mientras el segundo, Psicoanálisis directo. Teoría y práctica (tomo II) en 1977. Ambos fueron editados por Biblioteca Nueva, siendo supervisados técnicamente por el psicólogo clínico J. A. Portuondo, responsabilizándose de su traducción el también psicólogo F. Tamames. De hecho, Portuondo, como Rosen afirmaba en 1981, fue el artífice de la creación del instituto psicoanalítico directo en Barcelona y de sus homólogos en Madrid y Valencia. Esto explicaría el viaje que en 1979, según manifiesta Rosen, un grupo de 12 profesionales españoles realizó a Doylestown (EE UU), sede de la fundación Doylestown, entidad no lucrativa patrocinadora de actividades científicas y educativas en el campo psiquiátrico, al igual que en otros saberes, para allí recibir un seminario intensivo de 14 días de 
ORIGINALES Y REVISIONES

duración, en el que fueron instruidos teórica y clínicamente en el psicoanálisis directo, sin que para ello existiera cortapisa alguna si uno era médico, psicólogo o bien licenciado en alguna disciplina afín válida para recibir tal adiestramiento. Otros lugares donde también se crearon institutos fueron Francia, Puerto Rico y Nueva Delhi, en la que el Dr. Raj Bathia asumió la dirección de tal institución clínico-formativa (6).

El auge que va adquiriendo Rosen con tal innovadora técnica de tratamiento de la esquizofrenia hace también que entidades y fundaciones como la Rockefeller, Duke o la caritativa Webster, patrocinen la creación del Instituto de análisis directo, estableciéndose como sede de éste el centro médico de la universidad de Temple en Filadelfia (Pensilvania) (1). Según refiere el propio Rosen, entre sus objetivos figuraban: el estudio de las distintas técnicas usadas en el psicoanálisis directo, la evaluación de los resultados de tal intervención clínica aplicada a psicóticos, y la viabilidad y alcance real que su enseñanza-transmisión tendría en residentes y profesionales de psiquiatría. De esa época, en lo que parece ser un ejercicio de inmodestia, manifiesta también la inquietud que sentía por hablarle a C. G. Jung de todo ello, o tal vez corrigiéndose que éste se molestara contactando con él (8). Al respecto, fruto de comunicaciones personales, en 1954, Rosen afirma que Jung le confesó que Freud había llevado a cabo "un reconocimiento de sus síntomas", sin alcanzar comprensión profunda de su origen, como que el padre del psicoanálisis podría haber disentido con Jung en lo qué ambos entendían por tal comprensión.

Sea como fuere, el citado Instituto, según O. Spurgeon English, por entonces director del Departamento de psiquiatría de la facultad de Medicina, al que también se le nombró director de tal Instituto, se creó en junio de 1956 para, en colaboración con tal departamento, realizar un proyecto de investigación de 3 años financiado por la fundación Rockefeller, entidad que para ello aportó 150.000 dólares (12); se creó asimismo un comité de tres expertos, dos de ellos eminentes psiquiatras, K. Appel y R. Bookhammer, director el primero del Departamento de psiquiatría en la facultad de Medicina de Pensilvania, mientras el segundo lo era del Instituto psicoanalítico de Filadelfia, y un psicólogo, I. Lorge, catedrático de psicología en el Departamento de educación de la universidad de Columbia (13). Con ello se pretendían erradicar las dudas acerca de la parcialidad de tal comité, entre cuyas funciones estaba la de evaluar el trabajo de Rosen (director del programa de adiestramiento terapéutico y tratamiento) con psicóticos. Éste, al que en 1956 se le nombró profesor asociado de psiquiatría en la facultad de Medicina, 3 años después llegaría a ser presidente de la fundación de salud y retraso mental ubicada también en Filadelfia. En sus años como docente universitario, según O. S. English, él y Rosen trabajaron juntos 10 años, que comenzaron en 1955, terminando dos lustros después, al dejar English su dirección, 
ORIGINALES Y REVISIONES

aunque hay quien sitúa tal hecho un año antes, en 1964 (10). De esos años, este último recordaba retrospectivamente lo interesante que eran las ideas de Rosen acerca de la conducta y pensamiento psicótico, pues, según él, en contra de lo que muchos de sus colegas pensaban en los años 30 y 40 de que los psicóticos eran muy sensibles y fácilmente traumatizables, aquél con su trabajo clínico parecía desmentir esto (14). En ese ínterin, tampoco faltaron serias acusaciones respecto a la profesionalidad de Rosen, que fue denunciado por fraude y mala praxis médica por Alice Hammer, una de sus ex-pacientes, y el padre de ésta en 1955, lo que le conduce a un proceso legal que comenzará el 3-IV-1959, cuyo veredicto apelaron los demandantes, admitiéndose tal apelación el 7-I-1960, siendo ésta resuelta el 3 de marzo de ese mismo año (15). En tal juicio, conocido como $\mathrm{Ha}$ mmer vs. Rosen, éste fue acusado de golpear en diversas ocasiones a su paciente, alegando en su defensa que los progenitores de ésta conocían las implicaciones de tal tratamiento, aceptando así que a su hija se le propiciaran golpes, si ello servía para curarla, de lo que eran evidencia los moratones que presentaba en distintas partes del cuerpo $(10,15)$. El análisis directo de Rosen era así la terapia alternativa a las entonces en uso que aquél ofreció a tales padres angustiados, quienes antes habían visto como su hija había recibido 150 sesiones de terapia de electrochoque, si bien después se señala que fueron al menos 200, sin que fuera evidenciada mejoría alguna. A esto la defensa de Rosen arguyó que no había testimonio experto alguno apoyando las acusaciones de que tal terapia hubiera constituido fraude o mala praxis, de ahí que se desestimase la declaración de algún experto acerca de ello y/o la competencia médica de Rosen (16). Quienes, sin embargo, sí testificaron fueron primero H. Louise Wong, enfermera que atendió a Alice durante 12 días en septiembre de 1948, que relató como condujo a aquélla 2 veces a la consulta del Dr. Rosen, a quien la primera vez le pidió estar presente, negándose éste arguyendo que no permitía tal cosa a nadie, ordenándole que volviera por la paciente transcurrida 1 hora; 15 minutos después, Wong refiere como escuchó los fuertes gritos de Alice, intentando sin éxito acceder a la consulta del Dr. Rosen, al estar la puerta cerrada, pidiéndole aquél que se fuera. Terminada la sesión, Wong afirmó cómo se percató de que el cuerpo de Alice estaba cubierto de magulladuras y sus ropas rasgadas y desaliñadas. Asimismo, la madre de ésta informó que su hija tras recibir tratamiento regresaba a casa con signos evidentes de haber sido golpeada, señalando también Emma Reitz, empleada del hogar de los Hammer, cómo fue testigo, en el estío de 1950, en B. Landing (Nueva York), de cómo Rosen, injustificadamente, abofeteaba a la hija de sus señores (15). Finalmente, el jurado falló en contra del acusado, al juzgarlo responsable de un delito de agresión (battery), al entender que los golpes propiciados a Alice de 1948 a 1955, en que duró la terapia, cuyo coste superó los 55.000 dólares, constituían un tratamiento poco apropiado y negligente, lo que sin duda abría un 
ORIGINALES Y REVISIONES

debate acerca del consentimiento informado en psiquiatría y otras especialidades médicas $(17,18)$.

Al respecto, Dörr (19) también afirma la gran repugnancia que le produjo leer detalles de acciones legales posteriores, cuya puesta en marcha se realizó merced al trabajo de investigación de una detective privada, Virginia Snyder (10), con quien contactó Sally Zinman cuatro años después de terminar su tratamiento con Rosen, como más adelante señalamos, quien emprendió una investigación, si bien ya hacía muchos años que Rosen aplicaba sus técnicas psicoterapéuticas sin control alguno. Paralelamente, Rosen sigue trabajando y escribiendo, apareciendo en 1962 su libro Psiquiatría psicoanalítica directa (4), cuya dedicatoria es para sus tres hijos Richard James, John David y Alice Nancy. Originalmente pensada según el propio autor refiere en su prefacio para completar su obra anterior Análisis directo (1953), más que un complemento, como también Rosen dice, constituye una reexposición teórico-procedimental de lo que resulta esencial en tal intervención terapéutica, a la vez que revisa concepciones previas y añade material clínico novedoso. Asimismo, dos años después, concretamente los días 11 y 12-IX-1964 se celebra en Roma el I Congreso internacional de psicoanálisis directo, cuya apertura corrió a cargo de su creador y del Dr. Spartaco Scarizza (11), miembro de la Asociación psicoanalítica de Italia, que agradeció a la fundación Doylestown de Pensilvania esponsorizar tal evento, para después dar la palabra a los ponentes, comenzando por H. F. Searles que expuso las actitudes-responsabilidades que deben asumir los terapeutas que trabajan con psicóticos; tras lo que O. Sagredo habló de su particular visión acerca de la relación terapéutica, abordando luego L. S. Kubie el peso que en el terapeuta ejercen las necesidades/demandas que el sujeto coloca sobre él, expresando aquí E. Servadio su disconformidad con la opinión común acerca del frío rol terapéutico atribuido al psicoanalista clásico. H. A. Rosenfeld, por su parte, se ocupó de arrojar algo de luz respecto a la compleja/inextricable personalidad del individuo psicótico, del que Rosen señaló las muchas características neo-infantiles de su carácter, para centrarse después D. Rubinstein en sus investigaciones acerca de familias de/con psicóticos. Otras cuestiones de interés fueron la calidad/cantidad de interacciones sociales que el psicótico tiene a lo largo de su ciclo vital, como las manifestaciones agresivas que pueden desplegar y los ayudantes que podrían ser necesarios para hacer frente a tales eventualidades, que discutieron extensamente los doctores L. Ancona, I. Tolentino y C. Modigliani. El psicoanálisis directo fue examinado por L. H. Bartemeier, generándose entre todos los asistentes un clima estimulante y fructífero que propició el debate de estos y otros tópicos vinculados con el tema congresual. A su término, Rosen agradeció a todos los congregados, y en especial al Dr. Scarizza, máximo responsable de la organización de tal evento, su gran esfuerzo realizado en los preparativos y desarrollo exitoso de 
ORIGINALES Y REVISIONES

tal encuentro científico. Señalar, también, el tributo profesado en tal congreso a Marguerite Séchehaye, que debía participar y no lo hizo al fallecer el 7-VII-1964, proponiendo Kubie y secundando los demás enviar sus sinceras condolencias a familiares y amigos ginebrinos a través de Raymond de Saussure (1884-1971), presidente entonces de la Asociación psicoanalítica Suiza.

Seis años después, en 1970, el nombre de Rosen figura entre uno de los terapeutas controvertidos todavía vivos en EE UU, distinguiéndosele también como hombre del año en la academia estadounidense de psicoterapia en 1971 (20). Junto a tales reconocimientos, vuelve de nuevo a salpicarle otro caso clínico de abuso en el ejercicio terapéutico, como es el de S. Zinman, una joven a la que trató de 1971 a 1973, a la que según parece tras desnudarla y dejarla en ropa interior inmovilizada, la golpeó en el rostro y pechos (21), manoseándole también la vagina (22), tras lo que la maniató a la cama y la confinó en tal espacio terapéutico. Tales maniobras físicas, sin duda alguna cuestionables éticamente, eran combinadas con la tenaz lucha de Rosen para abolir el sistema interno de creencias de la paciente, a la que le ofrecía otro que debía interiorizar y guiar su patrón de conducta. Otro paciente de esos años fue Ted Schwartz, un anciano que falleció en la misma estancia donde había estado retenida Zinman, cuyo certificado de defunción había firmado Rosen, aunque de ello, como declaró luego Merry Humose (23), antigua empleada de éste, al departamento de Bienestar Público de Pensilvania, ella y otros no tenían noticia, al comunicárseles que Ted había regresado a su casa y no fallecido como después sabrían. Acerca de esto, Rosen manifestó que aquél había muerto a causa de una arterioesclerosis mientras era allí atendido de una psicosis senil. Denunciado esto en el Miami Herald y en el Philadelphia Inquirer en 1977, tales publicaciones fueron acusadas por Rosen de difamación, declarando éste acerca de tales hechos el 2 de marzo de 1981 según recoge el tribunal encargado de ello en Pensilvania (10).

Durante ese ínterin, concretamente el 26 de diciembre de 1979, Gay Claudia Ehrman, artista neoyorkina y paciente de Rosen, a quien se le habían asignado dos terapeutas mujeres; Robin Samuels, estudiante de psicología (24) y Carmen Patete (25), fue hallada muerta en su habitación, revelando la autopsia que existían varias magulladuras y diversos golpes recientes en el torso y abdomen, al igual que en las extremidades y cabeza. El hígado, también, a nivel interno, se mostraba en extremo lacerado, evidenciándose un hemoperitoneo masivo con hematoma retroperitoneal. Como causa de la muerte se señalaba las referidas laceraciones en el hígado, cuyo origen se atribuía a los traumatismos recibidos por golpes en el abdomen. Según lo publicado en distintos periódicos $(9,26,27,28$, $29,30,31$ ), con el objetivo de sacar a tal paciente de su mutismo, y en ausencia de Rosen, mientras Robin inmovilizaba a Claudia, Carmen le propinaba golpes; condenada la primera a 1 año por agresión bajo libertad vigilada, lo que consiguió 
ORIGINALES Y REVISIONES

tras pactar con el ministerio fiscal atenuar su condena, acusando de tal muerte a su compañera, aunque admitiendo que ésta no había deseado matarla, Carmen fue condenada a 8 años por homicidio involuntario. En este caso, a diferencia de otros, ya que llegaron a denunciarle hasta 11 pacientes, según informaciones publicadas, según recogía el 3-IX-1981 el Miami Herald, se alcanzó un acuerdo extrajudicial mutuo entre los padres de Claudia y la compañía aseguradora de Rosen, que, aún sin haber participado directamente en lo sucedido, reconoció públicamente su responsabilidad médica y los excesos de sus ayudantes con resultado de muerte, siendo así indemnizados los progenitores de su antigua paciente fallecida con 100.000 dólares. Varios meses antes, también, el 24 de julio, fue objeto de demanda judicial por otra ex-paciente, Janet Katkow, a quien trató de 1970 a 1979, y a la que al parecer obligó por mandato terapéutico a realizar ciertas prácticas sexuales con él y otras personas escogidas por Rosen. Otro caso que también salió a la luz fue el de Julia Blythe, quien estuvo bajo tratamiento con Rosen de 1963 a 1979.

Más allá de esto, en las fuentes consultadas, nada se sabe de nuestro autor, cuya muerte se produjo en 1983 (10), influyendo en ello tal vez la renuncia que hizo el 29 de marzo de ese mismo año a su licencia médica, que justificaba textualmente afirmando que ya era incapaz de ejercer la medicina con destreza y seguridad para sus pacientes (como consecuencia de su enfermedad), justo al traspasar el umbral generacional de sujeto octogenario; los 4 pacientes que aún trataba los derivó a los profesionales que juzgó aptos. Y es que con ello Rosen evitaba ser enjuiciado por el Consejo estatal de educación y licencias médicas del Departamento de Estado de Pensilvania, órgano que ya estaba preparado para acusarlo de 67 trasgresiones al acta de prácticas médicas de Pensilvania, como de 35 trasgresiones a normas y reglamentos del Consejo médico, lo que, dada su avanzada edad, como el gasto emocional y financiero parejo, posiblemente no deseaba otra vez enfrentarse. Una de tales acusaciones era la de ejercer como médico en Boca Raton (Florida) sin la correspondiente licencia médica, de la que sí disponía en Pensilvania, esgrimiendo Rosen al respecto que no la necesitaba, desde que sus pacientes se encontraban allí de vacaciones; otras fuentes periodísticas expresan, sin embargo, que solicitaba licencias municipales para edificios inexistentes, alquilando granjas de su propiedad a pacientes, sin que éstas constituyeran instituciones en donde se diera tratamiento mental alguno. Lo que sí pidió Rosen, y quedó pendiente, dadas las dudas que tal petición suscitó, era lo de convertirse en asesor-consultor de la comunidad para las personas mayores, al indicársele desde el Departamento de regulación profesional de Florida que, antes de la obtención o no del certificado de competencia, debería de indicar en su solicitud exactamente qué tareas y funciones asesora-consultivas realizaría, lo que no especificaba, mostrándose las autoridades reacias por si éstas resultaban 
ORIGINALES Y REVISIONES

ser de naturaleza psicológica, dada la historia previa del solicitante $(21,32,33$, $34,35,36,37,38,39,40)$. Por su parte, S. Zinman creó y pasó a dirigir la asociación en defensa de los pacientes mentales del condado de Palm Beach.

El análisis directo: una terapia de inspiración freudiana/kleiniana para la psicosis

Como bien refieren Roudinesco y Plon (5), el análisis directo consiste en una intervención psicoterapéutica activa, en la que el analista interviene de forma directa y a veces violenta, ofreciendo interpretaciones al paciente, frente al que ejerce en la transferencia el rol/posición de una madre idealizada o buena; cuya representación psíquica más primitiva y simbólica no es para Rosen (4) la imagen de una persona precisa e idealizada, sino la del pecho materno, a la que más tarde se la designará madre. La gran similitud de tales ideas con la noción kleiniana de posición esquizo-paranoide resulta evidente, faltando si cabe en Rosen el añadido de que el bebé no reconoce el objeto total (la madre como sujeto), sino dos objetos parciales (prototipo de los cuales es el pecho materno), uno al que juzga como bueno y otro como malo (aunque en ocasiones hay más de dos objetos); esto último, a nuestro entender, se puede atribuir a que, si bien Rosen la única referencia a la producción kleiniana que realiza es a El psicoanálisis de niños (1932), que cita en 1962 (4), y aun cuando tal obra sistematiza el pensamiento clínico que su autora venía gestando desde 1919, es posible que ignorara los desarrollos teórico-técnicos kleinianos posteriores, entre los que figura la delimitación de la posición esquizo-paranoide en 1946 (41), de ahí la justificada ausencia del añadido antes reseñado.

Sea como fuere, con la adopción de tal rol maternal, el psicoanalista directo lo que pretende es compensar el yo débil del sujeto, para lo que recrea la situación prenatal, a fin de superar/aliviar las profundas carencias afectivas originadas en la primitiva relación madre-bebé, al atribuir a la figura materna (o a quien la ostente) una incapacidad básica para amar y cuidar adecuadamente al hijo/a. El inicio de la esquizofrenia, visto así, se situaría en algún momento evolutivo entre el nacimiento y antes de la culminación del período preverbal (4), donde la actitud de rechazo y hostilidad maternal, llamada por Rosen perversión del instinto maternal, expresión que confiesa usa por conveniencia y no porque le atribuya a la misma una causa biológica, son interiorizadas por el neonato como el prototipo del tipo de interacción que marcará sus transacciones psíquicas con su realidad interna y externa. Tales ideas, como Rosen manifiesta, fueron gestándose poco a poco en su cabeza fruto del duro trabajo clínico con esquizofrénicos, además de por sus reflexiones teóricas, destacando en ello como germen su ensayo Método 
para resolver una excitación catatónica aguda, donde, ayudándose de conceptos psicoanalíticos, y para que los sujetos en tal estado retornaran a la realidad, asumía la identidad(es) de las figuras que parecían amenazar a éstos, dramatización con la que les aseguraba que, lejos de hacerles daño, tales figuras les amarían y protegerían. Según él, lograba así un contacto terapeuta-paciente en el que el fuerte ego del primero actuaba de sostén psíquico para el más débil del segundo, recayendo así la dificultad en suplir un ego patológico por otro sano, tratamiento de orden verbal alternativo a los entonces en boga como eran los sedantes, baños continuos, terapia de apoyo e ingesta forzada. Otro trabajo seminal ya mencionado es Tratamiento de la psicosis esquizofrénica con terapia analítica directa, del que, en el apartado final de discusión, P. Federn, entre otros, afirma que tal intervención consiste en atacar, usando la comprensión directa psicoanalítica, los eventos traumáticos vivenciados en la infancia, como si éstos aún pervivieran, dada la marcada regresión psíquica del esquizofrénico a los tempranos estados yoicos que conformaban su personalidad. Asimismo, señala el uso que Rosen hace de la transferencia positiva para tomar parte en la vida mental del paciente, para la que se sirve del saber psicoanalítico, aportando así un sentido a lo que, desde una actitud terapéutica distinta o lega, resultaría incomprensible de resignificar. En tal trabajo, también, en una nota a pie de página, Rosen expresa su gran gratitud a P. Federn por haber acuñado el término psicoanálisis directo, quien, a diferencia de aquél, cuya terapia supone un ataque directo al inconsciente tornado consciente, sin prestar por ello mucha atención a la repetición de la represión, la de Federn le otorga un papel significativo en el proceso terapéutico iniciado. Con todo, el propio Rosen reconoce que la etiqueta psicoanálisis directo resulta algo confusa, al hacer pensar que con ella se alude exclusivamente a interpretaciones directas, y no a una genuina actitud de falta real de formalismo y de proximidad en el abordaje-tratamiento del psicótico. Arguye también que por tales interpretaciones directas no deben entenderse fórmulas verbales para curar mágicamente a un sujeto psicótico, conformando un medio que el analista directo usa para convencer al sujeto de que realmente comprende, empatiza con, añadimos nosotros, su psicosis (4). De esta forma, a diferencia del psicoanálisis convencional, donde al neurótico le basta con adquirir el insight del significado de sus vivencias y conductas, eso, para Rosen, es del todo insuficiente en el psicótico, quien carece de las destrezas adecuadas para hacer consciente su propia psicodinamia. De ahí que, en contraste con el analista clásico, a su entender observador discreto de las sesiones clínicas, apueste por un rol más activo de éste en el psicoanálisis directo, al que distingue del psicoanálisis indirecto o clásico, que si bien juzga indispensable como método de investigación del psiquismo no como tratamiento psicoterapéutico, afirmando en defensa de su tesis: El psicoanalista directo sabe cómo intervenir, y sabe por qué es necesaria su intervención. El psicoanalista 
ORIGINALES Y REVISIONES

indirecto no interviene, ni comprende la necesidad de la intervención. Por el contrario, él presume que su intervención podría interrumpir algún proceso hipotético y misterioso de "recuperación”, que se supone está marchando-más o menos automáticamente- dentro del individuo. En un plano diferente, conviene también recalcar que, además de su inspiración kleiniana (5), algunos psiquiatras juzgan que tal técnica se nutre también de ideas ferenczianas, atribuyendo Masson (10) tal error a la aseveración de Rosen de que podía asistir a un psicótico durante 10 horas diarias, algo del todo imposible, pues para aquél ello limitaría seriamente el número de pacientes tratados. Tal aseveración, que Masson pensamos habría extraído del cuadro inserto en el artículo de Rosen Tratamiento de la psicosis esquizofrénica con terapia analítica directa (1947) (8), en el que éste, de un total de 37 casos tratados, refiere dos cuyo promedio de horas diarias de análisis directo era de diez, 15 años después, en su Psiquiatría psicoanalítica directa, afirma que la duración de las sesiones clínicas puede oscilar desde pocos minutos a varias horas, sin apenas pausa, aunque con algunos psicóticos señala pudiera emplearse como promedio una hora de sesión, a lo largo de 4-5 días a la semana, lo que para otros también afectaría a algunas noches durante varias semanas; siendo crucial en todo caso las necesidades del sujeto psicótico y el avance/retroceso terapéutico (4). Como dinámica, sin embargo, en que teóricamente sustenta el psicoanálisis directo, Masson señala la psicología onírica freudiana, expresando que, cuanta más atención prestaba al material clínico aportado por psicóticos, más similitud percibía Rosen entre éste y el facilitado por los sueños, vislumbrando así con su terapia una vía adecuada de despertar al psicótico de su interminable pesadilla o sueño salvaje, al tornarse entonces accesible el contenido real de su psicosis. De hecho, al poner en práctica el análisis directo, partía de la idea de que no había caso clínico alguno en el que el paciente no produjera algún material interpretable. De modo que, salvo patología física confirmada, la psicosis para él tendría un origen psicógeno, siendo abordada-tratada por métodos estrictamente psicológicos, pareciéndole así errado usar la etiqueta psicótico si el sujeto aqueja algún desorden/alteración orgánica.

En ese despertar al psicótico, es importante también la idea roseniana que neurosis y psicosis conforman un continuo, de tal forma que, si el sujeto retorna en su psiquismo a un estado previo de funcionamiento neurótico, la condición neurótica ahora retomada será diferente, dada las huellas dejadas por el tránsito psicótico y el tratamiento analítico directo, cuyo mayor beneficio terapéutico establece con el uso de interpretaciones directas a nivel oral, proceso de renacimiento y cambio personal al que denomina neoneurosis (8). Respecto a ésta, afirma que cuando inicialmente desarrollaba el psicoanálisis directo, creyó que, resuelta la psicosis con éste, salvo en situaciones de extraordinaria tensión psíquica, el antes sujeto psicótico estaría inmunizado para ser presa de nuevo de la 
psicosis; de ello, cuando así era posible, Rosen se aseguraba psicoanalizando a sus ex-pacientes psicóticos o derivándolos a un colega para que los sometiera a un psicoanálisis convencional. Años después, admitiría que, aún resultando eficaz, el psicoanálisis directo no confiere inmunidad, juzgando también que el psicoanálisis clásico no es el procedimiento más óptimo de realizar en la fase neoneurótica, proponiendo así otro tipo de refuerzo psicoanalítico más informal y personal (4), en el que el terapeuta actúe con un rol de carácter más activo, como el de un buen padre adoptivo, y no como el de madre-hijo que exhibía en el psicoanálisis directo cuando el sujeto estaba psicótico. De igual forma, como una de las primeras acciones del terapeuta señala incitar el interés del paciente por un síntoma que hasta ese momento éste había negado violentamente, que, en el caso de persistir, hacía que Rosen le hiciera creer que él también estuvo una vez psicótico y que manifestó los mismos síntomas, por lo que, como él, aquél también podría curarse, y, aunque una vez restablecido el psicótico advirtiera lo falaz de ello, resultaba positivo, al vivenciar éste que otro ser humano estaba a nivel emocional muy próximo a él. En el ataque al sistema delirante de sus pacientes también retaba a éstos a que por medio de ensayos conductuales dieran pruebas inequívocas de la realidad de sus delirios, para luego, fracasado esto, se mostraran más receptivos a escuchar y aceptar interpretaciones diferentes a las creadas por ellos respecto a su realidad delirante. Asimismo, ante la agresividad del sujeto en el inicio de su vuelta a la realidad, amenazaba a éste con pegarle más (y más fuerte) de lo que aquél le pegaría a su madre, esposa, etc., alentándole a redirigir sus impulsos agresivos, de necesitar expresarlos, hacia Rosen. Con ello, lo que perseguía era forzar al sujeto psicótico a que otra vez le prestara atención, utilizando los afectos displacenteros como una vía adecuada de contactar emocionalmente con él, que, en su retorno a la realidad, debía rechazar las voces y visiones que hasta entonces habían guiado su acontecer psíquico, aguijoneándole Rosen hasta obtener la plena certeza de que ya realmente no está dominado por aquéllas. En cuanto a la prognosis, afirma que los pacientes no sometidos a tratamiento de choque (ya eléctrico, insulínico, etc.) o maltrato institucional, responden mejor y antes al análisis directo. Asimismo, como un ingrediente facilitador del trabajo terapéutico refiere la capacidad del psicótico de verbalizar fácilmente su inconsciente, respecto al que Rosen actúa a nivel cognitivo como emocional, transmitiendo así al paciente además del significado consciente de sus acciones y pensamientos la resonancia emocional que unas y otros ejercen sobre el terapeuta y otros individuos próximos. Así, según él, uno no puede tratar a un paciente a menos que esté preparado para participar en la psicosis (8).

Vinculado con todo ello, es de especial relevancia el ambiente primigenio en que el psicótico fue nutrido cognitiva, social y afectivamente, como así aparece en el trabajo roseniano El concepto maternal de medio ambiente inicial en 
ORIGINALES Y REVISIONES

el psicoanálisis directo, en donde, a diferencia de ideas previas, Rosen defiende que el psicótico no busca a través de la fantasía una madre idealizada, sino un duplicado de la original, anhelo que conecta con los conceptos freudianos de transferencia y de compulsión a la repetición. Así, el psicótico lo que trataría es de revivir su relación temprana con tal atmósfera socio-emocional, y, especialmente, con la madre perdida que teme y a la vez añora/desea. A causa de esto, la teoría freudiana, es alterada, ejemplificando ello conceptos como neo-oral, neoanal o neo-latencia, que vincula con las primeras fases del desarrollo psicosexual, o que el complejo edipiano resida en ambos sexos en la dificultad para establecer una buena relación con la figura paterna, situando el origen del superyo, cuyo desarrollo concibe en tres fases (imitación, incorporación e identificación) poco después de nacer, como un proceso de asunción psíquica de la madre en el niño, ideas que resuenan a planteamientos kleinianos. La trama infantil edipiana, así concebida, supone para H. F. Searles (42) una excesiva simplificación de la misma, pues infravalora su significado, lo que atribuye a la gran preocupación de Rosen por la oralidad y otras fases pregenitales, abocándole así a no percibir la enorme angustia de castración que él implícitamente moviliza en su trabajo clínico si los pacientes no aceptan sus exigencias terapéuticas. El concepto de transferencia, cuya existencia juzga en y fuera de la sesión clínica, emerge desde la perspectiva roseniana de la gran necesidad del sujeto psicótico de maternaje, de ser proveído de amor/cuidados, que proyecta sobre personas, sustitutos en su universo psíquico de la primitiva figura materna, que vivenció como mortal pero indispensable; como sobre objetos, a los que confiere atributos maternales, de ahí que los fenómenos transferenciales-contransferenciales se movilicen con una intensidad mayor que la que acontece en el neurótico. A tal función terapéutica y abastecedora de alimento afectivo-vital para la psiquis del sujeto enfermo grave psíquicamente la llama Rosen psicotrófica, que literalmente dice significa que nutre el aparato psíquico (4). Tales necesidades, pues, de carácter permanente y duradero, vinculadas al nivel de los procesos primarios del psicótico, serían para este autor las señas distintivas de la transferencia, que no analiza, como tampoco las reacciones contratransferenciales, de tal suerte que los ingredientes agresivos, por así decir, negativos, de una y otras son reemplazados según el ya antes citado Searles (42) por una identificación muy patológica entre paciente y psicoanalista directo; por el contrario, eso no sucede en la terapia freudiana, cuya transferencia K. Menninger (1893-1990) juzga reposa en las identidades o roles inconscientemente adscritos al terapeuta, que, a diferencia de las necesidades, son temporales y responden a funciones del yo inmaduro (43).

Tras esta digresión, el ambiente maternal que se construye para el psicótico, partiendo del psicoanálisis directo, se constituye de una unidad de tratamiento, esto es, casa o apartamento individual, en donde, mientras dure la terapia, 
convivirá con terapeutas auxiliares, usualmente dos hombres y una mujer, que para ello han sido entrenados, con quienes seguirá el programa diseñado por el terapeuta principal o analista directo, madre adoptiva que, como el ambiente recreado, tratará de proveer al sujeto de aquellos cuidados físicos y afectivos de los cuales careció al comienzo de su vida, restañando así las fallas/deficiencias maternales de sus primeros años extrauterinos. Como indicios de tales mermas, Rosen atribuye un papel crucial a los actos verbales/no verbales desplegados por el sujeto en ese espacio vital, a los que el analista directo deberá prestar una especial atención, al igual que a los estudios evolutivos que investiguen la influencia benéfica o dañina que ciertos patrones de interacción de los padres, especialmente del hacedor de la función materna y del entorno de crianza, ejercen en el ulterior desarrollo psíquico y emocional del infante. En tal unidad, al psicótico se le prestará una atención continuada, velando así para que no se lesione, cometa autolisis, de la que Rosen informa haber tenido tres casos de suicidio consumado a lo largo de su experiencia clínica (4), o haga daño a otros y al entorno, estando para tal fin aquélla equipada con camisas de fuerza, esposas para manos y tobillos, además de llaves y sistemas de cierre en puertas exteriores como en la habitación del psicótico; tales recursos, de carácter excepcional, sólo serán usados cuando otros muestren ser ineficaces. Durante su estancia, el analista directo visitará al psicótico al menos una vez al día, pudiendo tal número ampliarse en función de las necesidades de aquél y de la disponibilidad del analista, al poder éste tener más sujetos a su cargo. Al psicótico debe también hacérsele ver que quien allí ejerce el completo control y total autoridad es el analista directo, cuya conducta siempre estará guiada a preservarle y cuidarle. Asimismo, si las circunstancias lo aconsejan, los asistentes y el psicótico pueden realizar juntos actividades externas, como son salir de compras, ir al cine, etc.; lo que sin duda se asemeja a planteamientos y prácticas actuales como, por citar un ejemplo, las que lleva a cabo la Fundación Andaluza para la Integración Social del Enfermo Mental (FAISEM), entidad responsable de la gestión de los recursos de apoyo social para personas con trastornos mentales graves. Igualmente, son permitidas las visitas de familiares y amigos a la unidad, aunque limitándose su número a unas pocas hasta que no se resuelva la psicosis. En tal sentido, se prohíbe, hasta lograr esto, que la madre real visite a su hijo/a, al adulterar ello el tratamiento-relación vincular con el analista directo, quien, para romper las ataduras libidinales con la figura materna y establecer nuevos lazos libidinales con su paciente, ataca la madre perversa, esto es, el superyo original sádico del sujeto psicótico.

Terminado así el tratamiento, para lo que será también preciso contar con el consentimiento explícito del psicótico, proceso cuya duración suele ser de semanas o meses o casos excepcionales un año o más, el analista directo planea las visitas de prueba que el sujeto psicótico realizará a su hogar, calculando para ello 
ORIGINALES Y REVISIONES

el riesgo potencial que tal cosa puede ocasionar, advirtiendo de ello a familiares y allegados, con quienes el analista se entrevistará, preparándolos de esta forma para el retorno de su familiar y, si fuera necesario, el reingreso de éste de nuevo en la unidad (4). Otros elementos del proceso psicoterapéutico que son objeto de su interés son los acting-outs y acting-ins, con los que designa ciertas conductas más propias del psicótico que del neurótico, que surgen como respuesta a sus deseos y sueños, sin que para ello cuente la realidad, juzgando a los primeros como un indicador de éxito clínico, merced al cual el sujeto bajo tratamiento manifiesta sus deseos reprimidos, disueltas las resistencias yoicas por una actuación más activa del terapeuta, todo lo que se aleja de la concepción psicoanalítica clásica de espejo de éste en el proceso analítico. Y es que, según Rosen, de adoptar el analista un rol activo, que asemeja al de un sustituto familiar, cabe esperar un mayor éxito terapéutico (8). Tales ideas, hoy, son compartidas por algunos, quienes juzgan tales exoactuaciones como una expresión de la evolución positiva de la cura, al implicar cierta forma de contacto del yo con el deseo inconsciente rechazado, permitiendo esto pensar que la defensa se ha resquebrajado. Asimismo, se considera que el acting-out es un elemento más de expresión y/o comunicación, por lo que es posible su tramitación analítica, siempre que su irrupción sea moderada e infrecuente. En cuanto al acting-in, Rosen reserva este término para las exoactuaciones psicóticas, mientras el de acting-out para las de naturaleza neurótica, al significar justamente in lo que emana de dentro e ignora la realidad, tal como sucede habitualmente en la producción onírica. Otros analistas, sin embargo, abogan por el uso exclusivo del término acting-out (44).

En otro plano, Rosen invita a quienes tratan a psicóticos que estudien sus cambios conductuales, ya durante semanas, ya en meses, pues, aun cuando no evidencien alteraciones cognitivo-conductuales en todos los casos, corroborarán cómo un sujeto inicialmente maníaco después está deprimido (8); y posteriormente paranoide o hebefrénico, pudiendo también hallarse otros tipos de combinaciones. De tal posible evolución y fases, con aparente pesar, manifiesta haberlas expuesto durante muchos años a sus colegas psiquiatras, renuentes a su aceptación, ya que como él mismo reconoce, de ser admitidas, llevaría a la psiquiatría aún más lejos de la noción médica de las entidades de la enfermedad diferentes en la psicosis, como debate en su trabajo titulado Algunas observaciones sobre la concepción de Bleuer de la demencia precoz, incluido en Análisis directo: artículos escogidos (1953). Así, por ejemplo, en lugar de juzgar a la psicosis maníaco-depresiva o a la hebefrénica como un tipo de enfermedad mental, las contempla como dos tipos de indicadores distintos, que sitúa en una escala de mayor o menor regresión-progresión psicótica. Propone, de este modo, ocho fases, fundamentalmente de carácter pregenital (anal y oral), aunque pudieran también hallarse signos de genitalidad, atribuyendo a cada una de ellas lo que de- 
nomina un motivo, esto es, un conjunto de sentimientos/ideas propios del sujeto psicótico en esa fase (4); y sólo para facilitar el entendimiento de su propuesta, sin pretensión diagnóstica alguna, coteja la clasificación tradicional de la psiquiatría descriptiva con la por él ofertada. El sujeto menos psicótico, por tanto, correlacionaría con la reacción maníaco-depresiva, tipo deprimido; reflejándose su motivo según la comprensión del analista directo de su paciente en: estoy soñando que estoy llorando (porque he perdido el pene, las heces y el pecho); esta máxima, como otras, le permiten al terapeuta tratar de entender qué sucede en el interior del psicótico, admitiendo con todo Rosen el carácter especulativo de tales afirmaciones. La siguiente, reacción maníaco-depresiva, tipo maníaco; tendría como motivo: estoy soñando que estoy muy vivo (porque estoy fingiendo que estoy unido con el pene, las heces y el pecho); en donde fingir es usado dada la falta de convencimiento del sujeto psicótico de que realmente lo que desea que sea cierto lo sea realmente. A la tercera fase, por su parte, la vincula con la reacción esquizofrénica, tipo paranoide; sintetizándose el motivo en: estoy soñando que estoy herido o amenazado de serlo (por tanto, mi problema es externo y no interno); mientras que a la cuarta fase, que correlaciona con la reacción de la fase anterior, el motivo sería: estoy soñando que yo sé qué hacer (porque he resuelto mi especial importancia en el mundo); siendo aquí donde el sujeto presenta un delirio sistematizado, tal como yo soy Jesucristo, que Rosen (4) concibe como un serio intento del psicótico por explicarse lo que ha estado vivenciando. La quinta estaría asociada con la reacción esquizofrénica, tipo hebefrénico; acogiendo el motivo: estoy soñando que soy un bebé tonto, riendo y jugando con dedos y pies (porque estoy tratando de fingir que soy el mundo entero). El sujeto, aquí, estaría fundamentalmente en una posición acting-in, respondiendo a los estímulos provenientes de su universo interno, mostrándose así aparentemente indiferente a su bienestar físico (qué come, en dónde defeca, etc.). En la sexta fase, reacción esquizofrénica, tipo catatónico; el motivo discurriría por: estoy soñando que estoy casi espantosamente rígido (porque la madre rehúsa amarme a menos que yo me тиега), para con ello obedecer el mandato maternal del superyó de permanecer callado, quieto y en silencio para poder así ser amado. La séptima, por el contrario, aun correlacionando con la reacción descrita en la fase precedente, incorporaría al final de tal descripción excitación catatónica aguda, formulándose su motivo como: estoy soñando que estoy aterrado de mi madre y gritando por ella (porque ella es mortal e indispensable); alcanzando cotas extremas el pánico y terror vivido por el psicótico en esta fase. En la última, la octava, la reacción sería como la sexta, esto es, esquizofrénica, tipo catatónico; siendo el motivo ahora: estoy soñando que estoy espantosamente rígido (porque debo estar muerto para complacer a la madre); dice luego que de una psicosis funcional puede salirse, dependiendo tal reversibilidad y las perspectivas de éxito/fracaso terapéutico del 
ORIGINALES Y REVISIONES

tiempo en que el sujeto ha estado psicótico, señalando como factor clave la capacidad residual de éste para examinar la realidad externa, a la que juzga como un segmento/porción inconsciente del ego, el cual, a su entender, pudiera estar conectado con esa parte del aparato psíquico encargada de producir el contenido manifiesto de los sueños, como la cantidad/flujo mayor-menor de las asociaciones libres que tienen lugar en la situación analítica. El grado de deterioro psíquico también vendrá marcado por la insensibilidad y maltrato institucional, como por otras condiciones a las que el psicótico ha estado sometido.

En cuanto a la formación de los futuros psicoanalistas directos, expresa que puede realizarse tan rápidamente como la homóloga de los analistas clásicos o la de cualquier otra intervención psicoterapéutica en psiquiatría, resultando adecuada tanto para sujetos psicóticos como neuróticos, rechazando también que el análisis directo sea una forma imperfecta o incompleta de psicoanálisis clásico, convencido de que toda técnica, para ser realmente terapéutica, debe ser directa. En contra de ello cita a M. Ostow, que, en respuesta al artículo suyo Psicoanálisis directo, argüía que, aunque la técnica de Rosen esté sustentada en la teorización freudiana (8), la realidad es que lo que hace no es en absoluto psicoanálisis, mostrando por ello su satisfacción de que aquél dijera tan poco acerca de la aplicación del análisis directo al tratamiento de la neurosis, al entender que tal extensión terapéutica resultaba en sí misma demasiado horrible de contemplar. Desarrollos clínicos posteriores como la psicoterapia dinámica breve, y particularmente el llevado a cabo por uno de sus más prestigiosos terapeutas, H. Davanloo, echan por tierra tal negativo comentario de Ostow, pues, ciertas intervenciones directas de Rosen, recuerdan someramente las confrontaciones del terapeuta canadiense (44), resultando sin duda interesante que se elaborara algún trabajo conectando uno y otro enfoque terapéutico.

Vinculado con ello, critica el carácter sectario que caracteriza a los analistas clásicos, como la rigidez y larga duración de su formación-entrenamiento, juzgando en línea con hallazgos actuales de investigación en psicoterapia más importante las destrezas y competencias personales del futuro terapeuta que los ambiciosos y no siempre adecuados programas de formación de los institutos psicoanalíticos, para lo que realiza una revisión histórica desde los orígenes del saber freudiano hasta las posiciones revisionistas o desviacionistas generadas o impulsadas en el seno de la comunidad psicoanalítica a lo largo de su vida institucional. Como diferencia clave entre el psicoanálisis convencional y el psicoanálisis directo señala la de la mutua observación del tratamiento que se da en el segundo, a diferencia del primero, en que el analista supervisor, a raíz de lo que le relata su supervisado, debe inferir los aciertos y desaciertos cometidos en la sesión(es) clínica(s), mientras en el análisis directo el terapeuta formado exhibe cómo él trabaja, para después ser su pupilo el que lo haga, requiriendo ello a 
su entender un menor número de horas de análisis didáctico en comparación a las exigidas en el psicoanálisis freudiano. Recomienda, junto a esto, un extenso programa de lecturas y estudio de trabajos psicoanalíticos (entre los que cita $L a$ interpretación de los sueños y La primera etapa pregenital de la libido [1916], de K. Abraham), psiquiátricos y psicológicos (8). Asimismo, propone un programa de entrenamiento psicoanalítico ideal, donde inscribirse estudiantes de grado de medicina, psicología o algún campo afín, a quienes, durante 2 años se les exigiría dedicación parcial, facilitándoles así terminar sus estudios universitarios, si bien en las vacaciones estivales podrían trabajar a tiempo completo en una unidad de tratamiento. A su propio análisis se dedicaría un promedio de dos a cuatro horas mensuales durante los dos años del programa, aunque ello sería variable según lo que requiriera el aprendiz de terapeuta; durante el primer año, éste, en observar el tratamiento podría emplear alrededor de 20 horas semanales, iniciándose él como analista el segundo año, bajo la supervisión-atención de su analista formador. Así, con tan sólo 20-21 años, afirma Rosen, el sujeto estaría preparado para comenzar su práctica clínica, y no, indefinidos años después, como sucede en la formación psicoanalítica clásica. Añade, con todo, que, después de ese bienio formativo, el joven aprendiz, cara a la especialización de su praxis con adultos, niños, grupos, etc., debería continuar su formación teórico-clínica, siendo en tal punto importante el consejo de su analista supervisor, además de sus intereses, en tal elección.

\section{Hallazgos en la investigación de procesos-resultados al aplicar el análisis directo}

Antes de abordar lo más significativo de tales hallazgos, conviene recordar la matización realizada por P. Federn incluida en el escrito de Rosen Tratamiento de la psicosis esquizofrénica con terapia analítica directa, donde afirma que, a pesar de sus resultados alentadores, dado el peligro de muerte que existe en el tratamiento de esquizofrénicos y el apoyo teórico que tal terapia tiene en el psicoanálisis, ésta debiera ser aplicada por el momento por psiquiatras bien entrenados, que además fueran analistas cualificados. Vinculado con ello, es interesante también lo que en ese apartado final de discusión dijo Joseph L. Meiers, quien, para investigaciones futuras, y ante los resultados curativos de Rosen (8), se preguntó en qué medida éstos se debían al tipo de terapia usada o bien al elemento interaccional dramático que ésta conllevaba, en el que, sin duda, los rasgos de personalidad del terapeuta constituían un ingrediente significativo del éxito/fracaso terapéutico. Meiers, por su parte, en espera de tal escrutinio, aboga por la naturaleza dramática interaccional de tal técnica. Con todo, sin entrar a discutir 
ORIGINALES Y REVISIONES

el peso que uno u otro factor ejerce en los resultados terapéuticos obtenidos, W. A. Horwitz y otros en Un estudio de casos de esquizofrenia tratados con el análisis directo (1958), concluyen que, tras 10 años de seguimiento a 19 pacientes del total de 37 que constituían la población clínica de Rosen, no cabe apoyar el informe original realizado, pues, aun cuando muchos de los sujetos cuando éste se redactó habían mejorado, tuvieron recaídas posteriores, requiriendo ayuda psicoterapéutica, lo que evidenciaba una tasa de recuperación inferior a la hallada por Rosen (45). Se afirmaba también que gran parte de tales pacientes no eran realmente psicóticos, cómo que otros, al terminar el tratamiento, continuaban siéndolo. En su defensa, Rosen arguye la omisión en tal estudio de que tales diagnósticos no fueron realizados por él, sino por destacados miembros de las dos instituciones públicas de las que fue extraído el universo muestral para tal estudio (hospital estatal de Brooklyn y hospital e instituto psiquiátrico de Nueva York), de ahí que según Rosen era a ellos a quienes debían dirigirse tales críticas metodológicas, manifestando también la potestad de aquéllos y no suya de dar de baja a tales sujetos institucionalizados, dato también ausente del que cabría inferir la competencia de tal decisión a él (8). Como origen último de tales sesgos, nuestro autor atribuye la reacción emocional que su trabajo con el análisis directo suscitó, dado el ambiente antipsicoanalítico entonces prevaleciente en donde desarrollaba su actividad profesional. Asimismo, a modo de justificación, manifiesta el carácter rudimentario que en 1947 poseía su tratamiento clínico, para cuyo éxito/resolución terapéutica duradera, como años después se percató, se requería una aplicación continuada del mismo. A pesar de ello, en 1959, doce años después de aparecer publicado su artículo y un año después de ver la luz el trabajo de Horwitz y otros, Rosen supo del buen estado psíquico en que estaban 19 de los 37 sujetos cuyos casos clínicos le sirvieron para redactar su artículo, como los avances-retrocesos experimentados por los 18 restantes, a los que globalmente juzga como positivos. Ese mismo año, también, autoría de McKinnon, figura el trabajo Una evaluación clínica del método del análisis directo en el tratamiento de la psicosis (1959), en donde eran revisadas la naturaleza y etiología de tal trastorno, así como diversos contenidos del proceso analítico directo (resistencias-fenómenos transferenciales), sin que a nuestro entender aporte nada novedoso a lo ya dicho por el propio Rosen (46). Sí es de interés en cambio saber que en los comienzos de su práctica, Rosen, al igual que hacía Séchehaye (47), alentado por el maltrato institucional que en su opinión recibían los pacientes psicóticos, alojó de forma individual a algunos en su propio hogar, perfilando luego lo que constituyen las unidades de tratamiento, algo de lo que también nos informará Brand (3) y de lo que cabe ahora afirmar que no obedecía a un recurso literario efectista de éste, sino a un compromiso genuino y altruista del entonces incipiente psiquiatra Rosen. McKinnon también refiere que, terminado el trata- 
miento, muchos sujetos seguían en contacto con Rosen, a quien le consultaban acerca de distintas cuestiones vitales que les afectaban (45). Otra publicación reseñable es el libro de M. W. Brody Observaciones acerca del "análisis directo": La técnica terapéutica del Dr. John N. Rosen (1959) (48), cuyo germen fue los encuentros semanales que tuvieron lugar desde enero de 1957 a mayo de 1958 en el Instituto de análisis directo, en donde, tras ser testigos de una sesión clínica de Rosen, que solía ser grabada con magnetófono sin omisión alguna y/o filmada para su ulterior análisis teórico-clínico, éste, Brody, English, Scheflen y más tarde McKinnon, se reunían, pudiendo estar presentes otros observadores cualificados, debatiendo todos de lo impartido antes por alguno a modo de conferencia acerca del análisis directo. Y es que, hasta entonces, el único con una sólida experiencia clínica con el análisis directo era Rosen, lo que después de tal publicación cambia, al comenzar los psiquiatras antes citados a utilizarlo también. En el primer capítulo, La entrevista inicial. Técnicas de terminación, a su vez subtitulado distanciando al paciente de la psicosis, se expresa cómo Rosen se dirige inicialmente al sujeto para evocar culpa (a lo que se dedicará el tercer capítulo del libro titulado Manipulando los sentimientos de culpa), que no insights (48), juzgando para ello crucial suprimir toda manifestación externa de los conflictos internos que asedian al psicótico (4), en lo que resulta crucial la ayuda dispensada por terapeutas auxiliares presentes, que, de ser ex-pacientes psicóticos, son los más idóneos para acceder/comprender el inconsciente. Vinculado con esto, dice Brody que para Rosen la psicosis era una experiencia vital única, merced a la que cabe obtenerse una gran intimidad con el inconsciente, más honda que la lograda tras 3-4 años de terapia freudiana, lo que sin duda guarda relación con el ideario del movimiento antipsiquiátrico entonces en ciernes. Y si el capítulo dos aborda el encuadre, el cuatro lo hace de cómo alterar el superyo, lo que exige romper identificaciones previas, introyectando nuevos objetos o cualidades inherentes a éstos, de modo que el sujeto psicótico se identifique con su terapeuta. Acerca del estilo de éste, y concretamente de la actitud de Rosen en las sesiones clínicas, se centra el quinto capítulo, donde se manifiesta que se dirige al enfermo como alguien sano que habla un lenguaje loco, sin sentido; diluyendo así las fronteras clásicas de normalidad-anormalidad psíquica. Como colofón, el sexto y último capítulo aborda el manejo del material onírico, informándonos aquí Brody que durante cierto tiempo, John David, uno de los hijos de Rosen, trabajó en el Instituto (48). De 1959 también es el artículo de G. Devereux Un escrutinio psicoanalítico de ciertas técnicas de análisis directo (49), en cuya introducción aparece nítidamente su objetivo: examinar qué sucede en la interacción paciente-terapeuta cuando se usa tal intervención clínica; esto es, conocer su naturaleza analizando algunas de sus técnicas (como son el manejo de la transferencia o la buena disposición del terapeuta para compartir el sistema delusivo del psicótico, que 
ORIGINALES Y REVISIONES

semeja a la táctica ferencziana de las fantasías provocadas), como exigencia previa a la evaluación favorable o no respecto a su eficacia terapéutica. Considera, así, que el análisis directo constituye una terapia surgida de la matriz psicoanalítica freudiana, a la que enriquece y da una comprensión dinámica más profunda de la etiología, desarrollo y ulterior potencial reversión de la condición psicótica. Dos años después, dos libros más relativos a estas cuestiones aparecerán: Una psicoterapia de la esquizofrenia: el Análisis directo (1961), autoría de Scheflen (50), en el que destaca la sección II, titulada Técnicas y estrategias del análisis directo, la más extensa, al abarcar 7 de los 11 capítulos que sin contar los 2 apéndices finales conforman tal obra. Antes de aludir a ellas, decir que por la actividad clínica desarrollada en el Instituto de análisis directo (al que el Comisionado de salud mental había previamente declarado parte del hospital estatal de Filadelfia, para legalmente poder tratar a psicóticos) Rosen no percibía salario alguno, al ser gratuito el tratamiento recibido; como introducción a la sección II se afirma que el análisis directo consiste en una amplia variedad de técnicas, enumerándose hasta 16 técnicas de persuasión enérgica: 1. Prometer y recompensar (para lo que debe evidenciarse una mejora genuina y no disimulada del proceder psicótico); 2. Amenazar y castigar (ante recaídas y desobediencia de alguna regla, implicando en contadas ocasiones castigo físico; mayormente se le priva de su comida preferida, o se le amenaza con retirarle el amor/aprobación); 3. Sugerir e instruir (muy vinculada con la técnica 16; incluye respuestas kinésicas y paralingüísticas, como también manuales ideadas por Rosen en su labor clínica); 4. Coercer (a fin de evitar conductas psicóticas, forzando al psicótico a interactuar con patrones de acción más congruentes, vinculándose también con el analista directo. La coerción física era así sólo usada al pretender huir, suicidarse, destruir objetos y para que le prestara atención al analista); 5. Dar a cambio de; 6. Utilizar la presión grupal; 7. Ridiculizar, avergonzar y desacreditar (persuadiendo al psicótico a dejar síntomas, defensas, etc., reactuando para ello su psicosis, de la que aquél debe advertir su sinsentido); 8. Interrumpir y desviar la atención (virando para ello las temáticas del enfermo hacia otras elegidas por el analista, quien puede llegar a inmiscuirse y ser él el foco del discurso erigido); 9. Apelar y desafiar (en donde la razón, experiencia prepsicótica o sentimientos de culpa del psicótico resultan ser armas eficaces para quebrar su actual condición psíquica); 10. Ofrecer una opción aún más inaceptable (para lo que ante 2 alternativas inadmisibles el sujeto se veía "forzado" a aceptar la sugerida por Rosen); 11. Dar falsas explicaciones (haciendo que el sujeto captara su absurdidad, y tras debatirlas, aceptar su imposibilidad); 12. Imitar y caricaturizar; 13. Ejercer ciertos roles (adquiriendo consciencia de fantasías y sentimientos, como de la confusión en otros roles, v. g. sexuales); 14. Permitir al paciente acting-outs; 15. Reasegurar; y 16. Confrontar directamente e interpretar. La elección de una o varias técnicas 
ORIGINALES Y REVISIONES

recaía en Rosen, cuyo objetivo era establecer un vínculo emocional durante la terapia de carácter autoritario-dependiente con el psicótico, cuyo pensamiento y conducta permanentemente cuestionaba, evitando y/o alentando para ello ciertos patrones cognitivo-conductuales alternativos, de tal forma que los impulsos, especialmente los sexuales, fueran expresados por aquél de forma distinta, culminando el tratamiento sin retrocesos/regresiones psíquicas; en ello el analista directo también se ayudaría de tácticas psicoterapéuticas", que irían desde atacar la imagen maternal en el superyo, hasta fijar la atención en las potencialidades del paciente (4); sentándose Rosen habitualmente al lado de éste, sosteniendo sus manos o pasándole un brazo por encima, animándole también a que al despedirse (y decir adiós) de la sesión le besara en la mejilla o en la frente.

El otro trabajo también aparecido en 1961 es Análisis directo y esquizofrenia. Observaciones clínicas y evaluaciones, donde English y otros (51) sustentan que el objetivo principal del análisis directo es reemplazar actitudes y cualidades ausentes en la madre, lo que exige la renuncia del sujeto psicótico a sus fantasías infantiles, exhortándole así a exhibir una conducta más madura, de la que pueda inferirse la fase de la psicosis en que está, siendo clave para ello la respuesta dada por aquél al medio externo (4). En cuanto a los tres libros citados, es interesante mencionar la opinión de Rosen, para quien aún cuando tales publicaciones discrepan entre sí en aspectos procedimentales y de la teoría subyacente, parecían concordar en juzgar al análisis directo como una amalgama de técnicas, las cuales van más allá de la interpretación directa, soslayando así que sus resultados terapéuticos reposen en mayor medida en la actitud y/o personalidad del terapeuta, apuntando también las dificultades inherentes en la interacción diádica analista directo-psicótico durante la terapia (8). En línea similar, deben citarse otros trabajos de revisión y puesta al día como son Desarrollos recientes en análisis directo (1964) (52), título que juzgamos no es fiel a su contenido, que comenzando con los tempranos trabajos rosenianos acerca de la psicosis en la década de 1940, detalla a continuación cómo se creó el Instituto de análisis directo en 1956, como los distintos trabajos (libros, revisiones y/o artículos acerca de sus principios teórico-técnicos) que Rosen y otros cercanos a él elaboraron en torno a su tratamiento; el resto del artículo se divide en 2 partes, la primera que sintetiza la teoría sustentadora del psicoanálisis directo, mientras la otra se centra en el tratamiento, sin añadir nada nuevo a lo ya publicado. Por último, aludiremos al trabajo titulado Un estudio clínico continuado de cinco años de sujetos esquizofrénicos tratados con el "análisis directo" de Rosen comparados con otros de control (1966), en donde los que recibieron tratamiento no experimentaron mejoras significativas respecto a un grupo de control al azar o uno de control designado (53). 
ORIGINALES Y REVISIONES

\section{Conclusiones}

Resulta difícil pensar que quien se oponía contumazmente a tratamientos como el electrochoque o la insulina, argumentando para ello la insensibilidad del estamento médico-psiquiátrico para abordar y tratar ciertas patologías mentales, como así atestiguan asertos suyos como el que la humanidad del hombre con el hombre puede ser una especie de medicina para los individuos que han estado profundamente afligidos por la inhumanidad (8), arrogado de un muy loable pero insensato furor sanador, recurriera a procedimientos físicos agresivos que, con el objetivo terapéutico de acabar y/o revertir la psicosis, atentaban y transgredían los principios deontológicos que deben regir todo encuentro humano tecnificado como es el de un proceso psicoterapéutico. Por ello, sin caer en una postura hagiográfica, pero tampoco condenatoria de toda la obra de Rosen, creemos que resulta preciso desvincular la teorización y apuesta que realiza a favor de un tratamiento distinto de la psicosis, de lo que es su práctica clínica, donde antepone la eliminación de ésta a quien la aqueja, justificando así el uso de medidas coercitivas si con ello lograba tal meta terapéutica. Si es en ese sentido en el que Dörr (19) se refiere cuando señala el carácter perverso del análisis directo, asentimos en esto con él, cuestionando sin embargo su afirmación, al no haber encontrado evidencia seria firme, de que en tal terapia existiera aceptación consentida para que si así fuera preciso, como vía para mejorar conductas autistas y catatónicas, se diera algún tipo de intercambio sexual entre terapeuta-paciente. Parece, más bien, que, más que eso lo que se hacía era una dramatización cargada de lenguaje obsceno, a través de la cual, ayudado por su analista directo, el psicótico daba satisfacción simbólica, que nunca real, a los deseos-fantasías sexuales que le atormentaban y se juzgaba debía expresar (47, 48). En cuanto a Masson (10), para quien Rosen constituye un peligroso y violento guru que ha perdido el control de sí mismo, realizando así horrendos crímenes con sus pacientes, todo lo que califica de sadismo indisimulado, nos atenemos a lo ya antes dicho de la ciega y ávida hambre terapéutica de aquél por curar. Echamos en falta, sin embargo, que Masson en lugar de sustentar tales críticas al psicoanálisis directo en serios trabajos acerca de sus éxitos-fracasos terapéuticos, se ocupe más de los procesos judiciales derivados de tal praxis clínica, los cuales aborda de forma poco rigurosa y periodística-sensacionalista (contribuyendo así a dar una imagen no ajustada del análisis directo, al que los medios periodísticos, erróneamente llamaron terapia del conflicto, terapia física intensiva y sacar fuera el demonio del paciente), lo que a nuestro entender evidencia un claro afán descalificador hacia este autor y su trabajo, de lo ya el mismo Rosen era consciente al señalar la total ignorancia de sus críticos (8). Asimismo, de ser cierta la ficción literaria de su semblanza escrita por Brand (2), cuya constelación familiar está formada por un padre vio- 
lento y una madre poco afectiva, cabría conjeturar la identificación inconsciente de Rosen con la figura paterna, así como el gran anhelo interior que tenía de una madre cariñosa y receptiva, mermas en su desarrollo socio-emocional en las que se asentaría toda su teorización-intervención psicoterapéutica. Finalmente, creemos acertada la queja de Masson (10), que aboga por una mayor ética en el ejercicio profesional, sabedor del corporativismo y el mirar hacia otro lado que ocasionalmente se da en quienes día a día trabajan en el campo clínico (10).

\section{BIBLIOGRAFÍA:}

(1) Terapeutas y psicoterapeutas. John Nathaniel Rosen (1902-1983) (s. f.). Recuperado el 01IV-2008 de la http://www.indepsi.cl

(2) Brand, M., <<Note>>, in M. Brand, Savage Sleep, London, W. H. Allen \& Co. Ltd, 1968 (First British Edition, 1969).

(3) Brand, M. Sueño salvaje, Barcelona: Luis de Caralt, 1974.

(4) Rosen, J. N. Psiquiatría psicoanalítica directa. Madrid: Biblioteca Nueva, 1978.

(5) Roudinesco, E. y Plon, M. Diccionario de psicoanálisis. Buenos Aires: Paidós, 1998.

(6) Rosen, J. N. Direct Psychoanalysis. En R. J. Corsini (ed.), Handbook of innovative psychotherapies. New York: John Wiley \& Sons, Inc, 1981, pp. 241-251.

(7) Federn, E. Witnessing Psychoanalysis. From Viena back to Viena via Buchenwald and the USA. London: Karnac Books, 1990.

(8) Rosen, J. N. Psicoanálisis directo, 2 tomos. Madrid: Biblioteca Nueva, 1975, 1977.

(9) O'Hara, T. (1979, December 28). Police Probe Fatal Beating of Woman. Miami Herald.

(10) MASSON, J. M. Juicio a la psicoterapia. La tiranía emocional y el juicio de la sanación psicológica. Santiago de Chile: Cuatro Vientos, 1991.

(11) Scarizza, S. (ed.), Proceedings of the first International congress of direct psychoanalysis. Doylestown, Pennsylvania: The Doylestown Foundation, 1965.

(12) News and Comment. Psychiatric Quarterly, 1956, 30 (1), pp. 748-753.

(13) English, O. S. Clinical observations on direct analysis. Comprehensive Psychiatry, 1, 1960, pp. 156-163.

(14) English, O. S. How I found my way to Psychiatry. En Burton, A., \& Associates. Twelve Therapists. How They Live and Actualize Themselves. London: Jossey-Bass, Inc., Publishers, 1972, pp. 78-102.

(15) Hammer vs. Rosen (7 A. D.2d 216; 181 N.Y.S.2d 805; 1959. App. Div. Lexis 10072); y (7 N. Y. 2d 376; 165 N. E. 2d 756; 198 N. Y. S. 2d 65; 1960 N.Y. Lexis 1428).

(16) Cohen, R. J. Malpractice: A guide for Mental Health Professionals. New York: The Free Press, 1979.

(17) Alexander, G. J. y Szasz, T. S. From contract to status via psychiatry. Santa Clara Lawyer, 13, 1973, pp. 537-559.

(18) SÁncheZ-Caro Jesús y SÁnchez-CARo, JaVIER. El consentimiento informado en psiquiatría. Madrid: Ediciones Díaz de Santos, 2003. 
ORIGINALES Y REVISIONES

(19) DöRR, O. Espacio y tiempos vividos. Estudios de antropología psiquiátrica. Santiago de Chile: Ediciones Universitarias, 1996.

(20) Rogow, A. A. The Psychiatrists. New York: G. P. Putnam's Sons, 1970.

(21) Pallesen, T. (1977, September 28). Boca Psychiatrist Faces Investigations. Miami Herald.

(22) Roche, W. F, JR., O’Neill, A. W. and Ruane, M. E. (1982, August 29). Psychiatrist accused of patient abuse. Miami Herald, p. 1B.

(23) Psychiatrist Faces Charges. (1977, December 7). Miami Herald, p. 1D.

(24) I held Legs of Victim, Psychology Student Says. (1980, September 27). Miami Herald.

(25) O'HaRA, T. (1980, January 5). Investigate Doctor who lives in Boca. Officials probe home where woman died. Miami Herald.

(26) Police weigh charges as bruised patient dies. (1979, December 28). PB Times.

(27) Gran jury may investigate death of 31-year-old woman. (1980, January 4). PB Times.

(28) O'Hara T. (1980, February 5). Intense Therapy Session Caused Patient's Death, Prosecutor says. Miami Herald.

(29) O'Hara T. (1980, February 22). 2 Therapists Indicted in Beating Death of Patient. Miami Herald, p. 3C.

(30) Woodhams, M. A. (1980, November 21). Assistant to psychiatrist vividly tells of 'violent therapies` given to patients. Sun Sentinel.

(31) Swanson, D. J. (1981, September 3). Patient's death to cost insurer \$ 100000. Miami Herald.

(32) Part-time Boca physician object of conduct probe. (1977, September 29). PB Times.

(33) Podolsky, D. (1980, January 1). State Resume Doctor's Probe after Death. Post.

(34) Rothman, S. (1982, August 3). Ex-Boca Psychiatrist Charged in Patient Abuse. Miami Herald, p. B1, p. B2.

(35) Rothman, S. (1983, March 30). Ex-Boca Psychiatrist Surrenders License. Miami Herald.

(35) Pallesen, T. (1983, April 3). Rosen a figure in '79 Broward slaying; accused of 'beating devil out of patients. Miami Herald, p. 1B, p. 2B.

(36) Zinman, S. (1983, April 3). Lake Worth woman tells horror of Rosen treatment. Miami Herald, p. 1B, p. 2B.

(37) ElLison, J. (1983, April 18). Ex-Boca doctor enters guilty plea. PB Times.

(38) Pallesen, T. (1983, May 20). Psychiatrist who gave up license seeks to counsel elderly in Boca. Miami Herald.

(39) Ellison, J. (1983, May 20). Boca probes Rosen office bid. PB Times.

(40) Pallesen, T. (1983, June 8). Psychiatrist must get state certificate. Miami Herald.

(41) SÁnchez-Barranco, A. El psicoanálisis postfreudiano: la escuela kleiniana. Sevilla: Arquetipo, 1993.

(42) Searles, H. F. Direct Psychoanalytic Psychiatry. Books Reviews. International Journal of Psychoanalysis, 1964 (45), pp. 597-602.

(43) Rubinstein, D. Los métodos psicoanalíticos de John Rosen. En B. B. Wolman (dir.), Técnicas psicoanalíticas. Buenos Aires: Troquel, 1962, pp. 291-330.

(44) Sánchez-Barranco, A. Técnica psicoanalítica. Sevilla: Arquetipo, 1993.

(45) Horwitz, W. A., Polatin, P., Kolb, L.C., y Носн, P. H. A Study of Cases of Schizophrenia Treated by "Direct Analysis". American Journal of Psychiatry, 114, 1958, pp. 780-783.

(46) McKinnon, K. M. A clinical evaluation of the method of direct analysis in the treatment of psychosis. Journal of Clinical Psychology, 15, 1959, pp. 80-96. 
ORIGINALES Y REVISIONES

(47) Balbuena, F. Marguerite Séchehaye, una pionera en el estudio psicoanalítico de la esquizofrenia. Revista de la Asociación Española de Neuropsiquiatría, vol. XXIX, n 103, 2009, pp. 113-133.

(48) Brody, M. W. Observations on "Direct Analysis": The Therapeutic Technique of Dr. John N. Rosen. New York: Vantage Press, 1959.

(49) Devereux, G. A Psychoanalytic Scrutiny of Certain Techniques of Direct Analysis. The Psychoanalytic Review, 46b, 1959, pp. 45-65.

(50) Scheflen, A. E. A psychotherapy of Schizophrenia: Direct Analysis. Springfield, Illinois, U. S. A: Charles C. Thomas Publisher, 1961.

(51) English, O. S., Hampe, W. W., JR., Bacon, C. L., y Settlage, C. F. Direct Analysis and Schizophrenia. Clinical Observations and Evaluations. New York: Grune \& Stratton, 1961.

(52) Sullivan, C. I. Recent Developments in Direct Analysis. The Psychoanalytic Review, 51, 1964, pp. 382-400.

(53) Bookhammer, R. S. Myers, R. W., Schober, C. C., ANd Piotrowski, Z. A. A five-year clinical follow-Up study of Schizophrenics treated by Rosen's 'Direct Analysis' compared with controls. American Journal of Psychiatry, 123, 1966, pp. 602-604.

* FRANCISCO BALBUENA RIVERA: Psicólogo, Departamento de Psicología Clínica, Experimental y Social. Universidad de Huelva

Correspondencia: Francisco Balbuena Rivera, C/ Gólgota, nº 8, 2-D; 41007 -Sevilla; Correo electrónico: balbuena@uhu.es

En la elaboración de este trabajo deseo agradecer la ayuda prestada por el servicio de préstamo interbibliotecario de la Universidad de Huelva, y de forma particular, a Aurora Romero Rodríguez, que diligente y eficazmente buscó y localizó trabajos para mí.

** Recibido: 8/06/2009 